\title{
Publisher Correction: A guide to vaccinology: from basic principles to new developments
}

\section{Andrew J. Pollard (1D and Else M. Bijker}

Correction to: Nature Reviews Immunology (2020) https://doi.org/10.1038/s41577-020-00479-7, published online 22 December 2020.

In this Review, Figure 2 (in the row for 'Nucleic acid vaccine') incorrectly showed RNA as a double-stranded nucleic acid rather than a single-stranded nucleic acid. Also, in the left-hand panel of Figure 5 ('No vaccination'), the transmission of infection was incorrectly depicted from a susceptible individual to a diseased individual rather than from a diseased individual to a susceptible individual. These errors have been corrected in the HTML and PDF versions of the article.

https://doi.org/10.1038/s41577-020-00497-5 I Published online 5 January 2021

๑) Springer Nature Limited 2021 